\title{
Autism spectrum disorders: The collaborative roles of the psychiatrists, educators and parents
}

\author{
Shernavaz Vakil*, Evonn Welton \\ University of Akron, Akron, USA \\ Email: svakil@uakron.edu
}

Received 23 February 2013; revised 26 March 2013; accepted 3 April 2013

Copyright (C) 2013 Shernavaz Vakil, Evonn Welton. This is an open access article distributed under the Creative Commons Attribution License, which permits unrestricted use, distribution, and reproduction in any medium, provided the original work is properly cited.

\begin{abstract}
Autism is a complex disability that requires collaboration, consultation and communication for provision of optimum treatment and intervention. Both psychiatrists and educators are key to the well-being of children and their families and can work together successfully in a comprehensive framework. This article provides information and recommendations in order to bridge both disciplinary fields so that this framework can be established.
\end{abstract}

Keywords: Autism; Educators; Psychiatrists; Collaboration

\section{INTRODUCTION}

Autism, like other mental or developmental disorders, does not exist in isolation from the medical, educational, and familial environments. A significant advantage present for those with developmental disorders is the link with the educational setting. Consultation/collaboration with teachers, principals and school psychologist can be an invaluable resource for the psychiatrist for both assessment and on-going treatment.

\section{NEED FOR COLLABORATIVE ASSESSMENT}

Recent data from the Center for Disease Control indicates that approximately 1 in 88 children demonstrate autism spectrum disorders [1]. Therefore, it is very probable that a practice specializing in pediatric psychiatry will have several patients with autism spectrum disorders. It is important that the physician have familiarity with the educational system so that the child is provided the best possible medical and educational intervention.

It is further probable that the reason for psychiatric

"Corresponding author. referral may be due to acting out behaviors that impact learning and peer relationships in the school setting. Children with autism frequently display problem behaviors of concern, including aggression and noncompliance [2], stereotypy [3], and self-injurious behavior [4]. In addition, the intensity of these behaviors, or additional issues, may result in a serious threat to health and safety. For example, serious forms of self-injury, restricted dietary intake, and severe physical aggression often result in referral to the psychiatrist and others in the medical community.

In the case of those with milder forms of autism and/or adolescents, there may be a referral to either rule out or identify co-morbid disorders including, but not limited to, obsessive compulsive disorder, avoidant personality disorder, depression, or anxiety. In addition to those problematic behaviors found in children, adolescents often present with additional issues common to adolescents who do not have disabilities. For example, bullying and social/sexual issues may be especially challenging for students with milder forms of autism. Bullying is a serious issue with $77 \%$ of parents reporting that their child had been bullied at school within the last month [5,6]. In all cases, both accurate initial diagnosis and on-going communication for determination of treatment efficacy are essential [7].

In most cases, parents and caregivers will be providing information for initial assessment purposes as well as on an on-going basis. This is especially important as individuals with autism have limited expressive language skills and therefore, relying upon their report of subjective internal states may be very unreliable and invalid. While parents and caregivers are excellent sources of information regarding day to day functioning in the home setting, this information can be expanded upon or supported by accessing information from the school personnel. Autism, by definition, is characterized by qualitatively different social interactions and play [8]. The school 
setting, by definition, is the environment in which demonstration of those social and play activities expected of other children of the same age are essential. At times, the parent or caregiver may not recognize the degree or severity of these behavioral patterns as they simply are not as problematic in the home settings. At other times, the family may put few demands upon the child in order to minimize acting out [6].

As children become older, they demonstrate atypical social and play activities that will be recognized by the educator. Therefore, they may have already had some form of psychological/educational assessment prior to being referred to the psychiatrist. Most educational settings are now required to provide initial problem solving and intervention strategies prior to identification as a child eligible for special education services [9]. If identified as eligible, the school will also have an Evaluation Team Report (ETR) with multiple sources of information including standardized scores on measures of intellectual ability, academic achievement, adaptive behavior and receptive/expressive language, checklists, surveys, observations and interviews. This information can prove to be invaluable to the psychiatrist and medical team when planning treatment and intervention [7].

The ETR contains measures of intellectual ability, academic achievement, language skills and adaptive behavior and provides information regarding the level of performance in the school setting. While approximately $70 \%$ of children with autism demonstrate mental retardation others with more mild forms demonstrate a wide variety of scatter with some skills being significantly better developed than others [10]. Lastly, there are some that demonstrate islets of ability (savant skills) which have the sometimes misleading appearance of giftedness across all skills [11]

Most psychological/educational evaluations from the school also contain information regarding social skills and behavior. Educational personnel skilled with Functional Behavioral Assessment (FBA) and Applied Behavior Analysis (ABA) may prove invaluable to the psychiatrist. FBA provides objective and quantifiable data on the origin and reason for the behavior [12]. It identifies, to the best extent possible, the reason that the behavior is occurring and provides direction for services. For example, a child may be demonstrating inappropriate behavior in order to avoid tasks and requests, as a means to obtain a tangible goal such as food, or to obtain attention. In addition, some behaviors are not driven by anything environmental and rather arise from internal states. It is also important to know whether these behaviors are chronic or acute in nature. For example, a child who has a sudden onset of self-injury such as head hitting or hand biting, may be experiencing dental problems or headaches. Random aggression may indicate a form of sei- zure activity that requires a neurological consult or the onset of a psychotic disorder. Because of the aggression or self-injury, the child is then referred to the psychiatrist for medical management however, without adequate information from the school, appropriate treatment may not be easily identified and adjusted [13].

\section{THE NEED FOR COLLABORATIVE INTERVENTION AND TREATMENT STRATEGIES}

Within the school setting, the optimum form of service addresses the needs of the entire child. Much of the time, children with autism spectrum disorders are provided services in what is referred to as an "inclusive setting". This means that most, if not all, of the children's school day is spent with typically developing children and in the regular classroom setting. Lessons and assignments may be adapted to facilitate learning and completion. Direct instruction and programming may also be directed toward social skill development. The children's Individualized Education Plan (IEP) will reflect all services and objectives as identifies and agreed upon by the school and family. In other cases, children with autism may not be identified as needing any form of special education services and function relatively well with typically developing peers. While this is sometimes the case, children who has been referred for psychiatric intervention will more probably also be identifies as requiring special education [13].

Unfortunately, the IEP is a basic document that provides some, but not necessarily detailed information, for the psychiatrist. That is why the psychiatrist may want to access additional school information such as the Evaluation Team Report, if it has been completed. With permission, it may also be helpful to contact a principal or school psychologist as a point person from whom additional information may be obtained. This may be especially important for on-going data collection in order to determine the success of treatment strategies.

\section{THE NEED FOR COLLABORATION AMONG EDUCATORS AND PSYCHIATRISTS}

Taken in total, collaboration between the psychiatrists and educators should be an ongoing process, where they share their expertise to promote the success of students with autism. Educators and psychiatrists work closely to develop a continuum of services which promote effective prevention, assessment and intervention for students with autism in schools. Strategies to enhance partnerships between educators and psychiatrists to expand the range of services provided by schools must include a multidisciplinary approach which includes facilitating access to 
services through consultation, communication and professional competencies.

\subsection{Consultation}

School based consultations where medical personnel, such as psychiatrists and educators collaborate professionally to address concerns of clients are increasing. In traditional medical settings, psychiatrists work directly with children with autism in isolation. In a school-based consultation, psychiatrists work primarily with educators and parents who have direct contact with the children and play an important role in the intervention [14].

A variety of targeted educational accommodations may be implemented which address the concerns and benefits for children with autism. A focus on social and language intervention, adapting lessons using visual aids, and use of computers and media may all be beneficial for children with Autism [15]. The psychiatrists may be able to suggest these types of strategies during consults or team meetings. In addition, psychiatrists are very familiar with brain functions and may be of assistance for bridging the gap between educators and more medically based explanations.

Individual psychiatric services with children may also be beneficial. However, they should complement and reinforce goals on the IEP and include improving school performance, and teach skills which focus on social and language development. Care should be taken that goals are within a range that the child can accomplish. Additionally, psychiatric counseling can also be used to reduce anxiety and depression and improve socialization through cognitive-behavioral therapy and social skills training. Children with autism who are cognitively aware of their social difficulties and learning history tend to be more anxious and depressed. The demand for sophisticated social skills often overwhelms and confuses them which in turn exacerbates social deficits leaving them defensive and vulnerable [16]. Increasing social skills while reducing anxiety and depression could be more effective if done in the cultural context of schools and their expectations. Consultation between educators and psychiatrists are essential to social success for students with autism.

\subsection{Communication}

School-based consultation is interdisciplinary with professionals sharing expertise to make team decisions. Educators are generally responsible for collecting and sharing information, and planning and monitoring the effectiveness of interventions implemented in schools. Psychiatrists should participate actively in the identification of the problems associated with autism including comorbidity factors. Additionally, they may actively guide the behavior intervention plan focusing on specific be- haviors and alternate intervention strategies. Assistance may be provided to educators both formally through materials and resources and informally through phone calls and school visits [14].

There are often complex issues surrounding the diagnosis of autism and the subsequent intervention, and often the risk for team members and test interpretation is placing emphasis on either the individual areas of strength or weakness of the child rather than describing the child as a whole. Therefore, team members must carefully review and share clearly explanations of all areas assessed, pace the meeting slowly, and frequently check with all team members for the need for clarification and questions. Meetings such as the IEP provide a natural opportunity to clearly communicate goals and objectives and should be planned $[17,18]$.

Communication between school and psychiatry is also essential so that the psychiatrist better understands the context of the behavior and the school is aware of medication changes and other medical issues. Not only is this important for initial diagnostic assessment, but also for on-going determination of treatment success. It is important that all stakeholders consider themselves as part of the same team of professionals and freely communicate (with parental/guardian consent) as needs arise [7].

\subsection{Professional Competence}

Interdisciplinary participation is critical to effective interventions and successful team meetings. How educators and psychiatrists perceive themselves and each other significantly impacts participation and collaboration at team meetings. Mutual trust, respect and honesty between educators and psychiatrists enhance professional partnerships. Professionals must be willing to shed their preconceived notions and be willing to exchange information and listen to each other [18]. The expertise professionals may bring without a focus on the rigid boundaries of the roles they play increases the opportunities for optimal interventions [19].

Optimal professional competence should be characterized by clearly articulated goals shared by both educators and psychiatrists. These goals should be shared in an environment where team formal and informal expectations and norms are clarified. Language used at team meetings should always be professional and exclude a lot of the jargon, especially when parents or the individuals are present [20].

Finally, professional competence should be guided by principles which reflect ethical practices. These include but are not limited to making sure assessments and interventions do not harm students physically or emotionally, confidentiality, developing relationships with families and the student, advocate for the student and conduct 
one self and the team with integrity and professional judgment [21]

\section{CONCLUSION}

In conclusion we would like to emphasize the importance of collaboration between educators and psychiatrists to enhance interventions for individuals with autism. Literature reveals that collaboration is vital to optimize success. Psychiatrists and educators should function as part of a team where information regarding diagnosis and treatment are shared so that interventions are successful at both home and school. All team members should be encouraged to develop a sense of empathy for how the child processes information and their daily frustrations so that their individual emotional needs are addressed. While educators should access resources to enhance social and emotional skills in the school setting, psychiatrists should serve as valued consultants to guide educators in the educational arena.

\section{REFERENCES}

[1] Center for Disease Control and Prevention (2012) Prevalence of autism spectrum disorders-autism and developmental disabilities monitoring Network Center for Disease Control and Prevention. Morbidity and Mortality Weekly Report, 61, 2-19.

http://www.cdc.gov/ncbddd/autism/data.html

[2] Farrar-Schneider, D. (1992) Aggression and noncompliance: Behavior modification. In: Matson, J.L., Ed., Autism in Children and Adults: Etiology, Assessment, and Intervention, Brooks/Cole Publishing, Co., Pacific Grove, 181-191.

[3] MacDonald, R., Green, G., Mansfield, R., Geckeler, A., Gardenier, N. and Anderson, J. (2007) Stereotypy in young children with autism and typically developing children. Research in Developmental Disabilities, 28, 266277. doi:10.1016/j.ridd.2006.01.004

[4] Oswald, D.P., Ellis, C.R., Singh, N.N. and Singh, Y.N. (1992) Self-injury. In: Matson, J.L., Ed., Autism in Children and Adults: Etiology, Assessment, and Intervention, Brooks/Cole, Pacific Grove, 181-191.

[5] Cappadocia, M.M., Weiss, J. and Pepler, D. (2012) Bullying experiences among children and youth with autism spectrum disorders. Journal of Autism \& Developmental Disorders, 42, 266-277. doi:10.1007/s10803-011-1241-x

[6] Wheeler, J.J. and Richey, D.D. (2010) Behavior management: Principles and practices of positive behavior supports. 2nd Edition, Pearson.

[7] Chandler, L.K. and Dahlquist, C.M. (2002) Functional assessment: Strategies to prevent and remediate challenging behavior in school settings. Merrill Prentice Hall, Upper Saddle River.
[8] American Psychiatric Association (2000) Diagnostic and statistical manual of developmental disorders. 4th Edition, Author, Washington DC.

[9] Finkel, E. (2011) New directions for special Ed. District Administration, 47, 51-57.

[10] Beirne-Smith, M., Ittenbach, R.F. and Patton, J.R. (1998) Mental retardation. 5th Edition, Merrill/Prentice Hall, Upper Saddle River.

[11] Biever, C. (2009) The makings of a savant. New Scientist, 202, 30-33. doi:10.1016/S0262-4079(09)61515-3

[12] Love, J., Carr, J. and LeBlanc, L. (2009) Functional assessment of problem behavior in children with autism spectrum disorders: A Summary of 32 outpatient cases. Journal of Autism \& Developmental Disorders, 39, 363372. doi:10.1007/s10803-008-0633-z

[13] Mattila, M., Hurtig, T., Haapsamo, H., Jussila, K., Kuusikko-Gauffin, S., Kielinen, M. and Moilanen, I. (2010) Comorbid psychiatric disorders associated with asperger syndrome/high-functioning autism: A community- and clinic-based study. Journal of Autism \& Developmental Disorders, 40, 1080-1093. doi:10.1007/s10803-010-0958-2

[14] Sheridan, S.M. and Cowen, R.A. (2004) Consultation with school personnel. In: Brown, R. and Erlbaum, L., Eds., Handbook of Pediatric Psychology in School Settings, Mahwah, New Jersey \& London, 599-616.

[15] Wilson, K.P. (2013) Incorporating video modeling into a school-based intervention for students with autism spectrum disorders. Language, Speech \& Hearing Services in Schools, 44, 105-117. doi:10.1044/0161-1461(2012/11-0098)

[16] White, S.W., Ollendick, T., Scahill, L., Oswald, D. and Albano, A.M. (2009) Preliminary efficacy of a cognitivebehavioral treatment program for anxious youth with autism spectrum disorders. Journal of Autism and Developmental Disorders, 39, 1652-1662. doi:10.1007/s10803-009-0801-9

[17] Welton, E., Vakil, S. and Carasea, C. (2004) Strategies for increasing positive social interactions in children with autism: A case study. Teaching Exceptional Children, 37, 40-46.

[18] Green, J.A. (2008) Collaborating with special educators \& administrators, 2008. Principal.

[19] Turnbull, A., Turnbull, R., Erwin, E.J., Soodak, L.C. and Shogren, K.A. (2011) Families, professionals, and exceptionality: Positive outcomes through partnerships and trust. 6th Edition, Pearson, Upper Saddle River.

[20] Friend, M. and Cook, L. (2013) Interactions: Collaboration skills for school professionals. Pearson, Upper Saddle River.

[21] Kampwirth, T.J. and Powers, K.M. (2012) Collaborative consultation in the schools: Effective practices for students with learning and behavior problems. 4th Edition, Pearson, Upper Saddle River. 